\title{
Is Usual Dietary Pattern Related to the Risk of Developing Breast Cancer?
}

\author{
Jessica A. Lindgren • Jacqueline A. Vernarelli • \\ Jennifer Savage-Williams • Terryl J. Hartman
}

Published online: 5 February 2013

(C) Springer Science+Business Media New York 2013

\begin{abstract}
Dietary patterns capture total diet providing a more comprehensive understanding of the effect of diet on chronic disease risk. Dietary patterns have been associated with several chronic diseases, including cardiovascular disease and selected cancers; however, the association with breast cancer remains unclear. The objective of this review was to examine critically the most recent literature on dietary patterns and breast cancer and report on current results, new developments, and future directions. Seven case-control and cohort studies from multiple countries have been published during the previous year (2011-2012). Many have analyzed a posteriori dietary patterns via factor and principal component analysis. Whereas results remain mixed, the majority of studies indicate healthier patterns decrease breast cancer risk, although patterns higher in meat and alcohol increase risk. Future studies that examine the associations between diet and tumor subtypes and collect dietary data at younger ages and, if possible, longitudinally would be beneficial.
\end{abstract}

\author{
J. A. Lindgren $(\bowtie) \cdot$ J. A. Vernarelli \\ Department of Nutritional Sciences, The Pennsylvania State \\ University, 110 Chandlee Laboratory, \\ University Park, PA 16802, USA \\ e-mail: jal5150@psu.edu \\ J. A. Vernarelli \\ e-mail: jvern@psu.edu \\ J. Savage-Williams \\ The Center for Childhood Obesity Research, The Pennsylvania \\ State University, 129 Noll Laboratory, \\ University Park, PA 16802, USA \\ e-mail: jfs195@psu.edu

\section{T. J. Hartman} \\ Department of Epidemiology, Emory University, 1518 Clifton \\ Road NE, CNR \#3035, \\ Atlanta, GA 30322, USA \\ e-mail: tjhartm@emory.edu
}

Keywords Food patterns $\cdot$ Dietary patterns $\cdot$ Eating occasions $\cdot$ Breast cancer $\cdot$ Cluster analysis $\cdot$ Factor analysis . Diet patterns

\section{Introduction}

Breast cancer is the most commonly diagnosed cancer among women [1]. Alcohol consumption, physical inactivity, elevated postmenopausal body mass index (BMI) [1], early age at menarche, late age at menopause [2], family history, and genetic mutations [3] are a few of the well-established breast cancer risk factors. Dietary factors have been suggested as influential to breast cancer risk; however, in the recent World Cancer Research Fund (WCRF) review of the evidence, alcohol intake was the only factor shown to consistently increase risk [1]. Much of the dietary research has looked at specific foods or single nutrients. In recent years, the focus has shifted to the examination of whole dietary patterns to account for food and nutrient interactions that occur naturally in the diet. Dietary patterns also are able to capture variations in food consumption that occur across populations.

Dietary patterns can be derived in several ways; the most common are a posteriori methods, including principal component analysis (PCA) and factor analysis (FA). A posterori methods are data-driven and used to reduce the dietary data into a small set of uncorrelated variables that are more easily interpretable [4]. The data-driven approach often is considered to be "exploratory" [4]. A priori methods are scoredriven and hypothesis-oriented. These methods frequently use predetermined scores or indices that reflect nutritionrelated guidelines (e.g., HEI-2005) [4, 5]. Many types of scores and indices exist, and as a result, they emphasize slightly different foods (HEI-2005 vs. Mediterranean Diet Score), which make comparing dietary patterns across these scoring methods challenging. 
A 2010 review and meta-analysis of 18 case-control and cohort studies of dietary patterns and breast cancer risk in both pre- and postmenopausal women concluded that compared with women with the lowest adherence to the "Prudent/Healthy" pattern, those with the highest adherence had a decreased breast cancer risk [6••]. The opposite was true for the "Drinker" pattern with the highest alcohol consumers having a significantly higher risk of breast cancer than the lowest consumers [6••]. There was no association between breast cancer and the "Western/Unhealthy" dietary pattern in this review [6••]. The objective of the current review is to focus on and summarize the most recent literature on dietary patterns and breast cancer and report on current results, new developments, and future directions.

\section{Study Selection}

A literature search of the PubMed database of the United States National Library of Medicine was conducted to identify human studies that evaluated the associations between dietary patterns, both a posteriori and a priori, and breast cancer. Relevant studies were identified using the following search terms in multiple combinations: "food patterns"; "breast cancer"; "breast disease"; "eating occasions"; "cluster analysis"; "factor analysis"; "diet patterns"; and "dietary patterns." The search was limited to full-text publications written in English published in the past year (2011-2012). Women of all ages were included. From a total of 21 studies, 11 did not examine dietary patterns and 3 did not focus on breast cancer as an outcome. After all exclusions, seven studies were included in this review and are summarized in Table 1.

\section{Mediterranean Diet}

The Mediterranean diet is characterized by a high intake of vegetables, fish, legumes, and olive oil, which are high in polyphenols, omega-3 fatty acids, antioxidants, fiber, and other cancer-fighting dietary components that can reduce inflammation and prevent cellular damage [7••]. This diet is associated with a lower risk of several chronic diseases, including cancer and heart disease [8-10]. Three recent studies have examined the Mediterranean dietary pattern and its association with breast cancer risk [11-13]. Both $a$ priori and a posteriori methods were used. Demetriou and colleagues [11] conducted a population-based case--control study in postmenopausal women who were participating in the larger MASTOS study in Cyprus, Greece. Cases $(n=$ 935) had a confirmed breast cancer diagnosis between January 1999 and December 2005. Controls $(n=817)$ were recruited from the population who received a negative test result after attending the national mammography screening program. This study examined the compliance with the Mediterranean diet using both predetermined diet scores $[8,14]$ and an exploratory PCA method. Dietary data over the previous year were collected by an interviewer via a $32-$ item food frequency questionnaire (FFQ) developed to summarize the foods with the highest energy and nutrient contribution to the Cyprus diet. It is important to note that this FFQ encompasses a very small number of foods and often was completed several years after diagnosis, which may have introduced bias. A significant positive association between a PCA-derived Mediterranean dietary pattern and breast cancer risk was observed in a sample of postmenopausal Greek women [11]. Weak associations were observed between some of the individual components of both of the Mediterranean diet scoring methods and cancer risk; however, when combining the components into a dietary pattern, those with the highest adherence to the Mediterranean dietary pattern had significantly lower odds of developing cancer compared with those in the lowest quartile of adherence (odds ratio (OR) Q4vs.Q1 0.67; $95 \%$ confidence interval (CI) 0.49-0.92; $\left.\mathrm{p}_{\text {trend }} \leq 0.0001\right)$. Cade et al. [13] also examined adherence to the Mediterranean Diet Score (MDS) and the World Health Organization Healthy Diet Index (WHOHDI) and breast cancer risk in a cohort of 33,731 premenopausal and postmenopausal women from the United Kingdom Women's Cohort Study. The MDS was defined by Trichopolou and colleagues [15] and placed emphasis on legumes, fruits, vegetables, and fish among other foods. The WHO-HDI [16] scores participants based on their consumption of several types of fatty acids, cholesterol, total carbohydrate, fruits and vegetables, salt, and added sugar. After a mean follow-up period of 9 years, 828 breast cancer cases were diagnosed (ICD 9-10). Diet was assessed at baseline using a self-administered validated 219-item FFQ. This study found that higher adherence to the MDS was associated with a marginally lower risk of breast cancer among premenopausal women (hazard ratio (HR) 0.65; $95 \% \mathrm{CI}$ $0.42-1.02 ; \mathrm{p}_{\text {trend }}=0.09$ ), although this did not reach statistical significance. Bessaoud et al. [12] conducted a population-based case-control study using both PCA and variable clustering (VC) to derive dietary patterns in a sample of premenopausal and postmenopausal French women and evaluated their association with breast cancer risk. Briefly, VC, unlike cluster analysis, obtains food group variables and splits them into one group with characteristics that provide similar information versus a second group that exhibits radically different, yet complementary characteristics [12]. Unlike PCA, these patterns may be correlated. Recruitment of cases took place between June 2002 and December 2004; all incident breast cancers were included with the exception of lobular carcinoma in situ. Two ageand community-matched controls per case were randomly 
Table 1 Studies of dietary patterns and breast cancer

\begin{tabular}{|c|c|c|c|c|c|c|}
\hline Author, year & $\begin{array}{l}\text { Study } \\
\text { population, } \\
\mathrm{n}\end{array}$ & Design & Dietary patterns & $\begin{array}{l}\text { Dietary } \\
\text { assessment/ } \\
\text { outcome }\end{array}$ & Major significant results & Adjustments \\
\hline $\begin{array}{l}\text { Baglietto et } \\
\text { al. [20], } \\
\text { (Australia) }\end{array}$ & $\begin{array}{l}\text { Pre and post } \\
\mathrm{n}=20,674 \\
(31-76 \mathrm{y})\end{array}$ & PCS & $\begin{array}{l}\text { 1) Vegetable; 2) Fruit and salad; } \\
\text { 3) Traditional Australian; 4) } \\
\text { Meat }\end{array}$ & $\begin{array}{l}\text { 121-item } \\
\text { FFQ/BC }\end{array}$ & $\begin{array}{l}\text { Fruit and Salad Pattern: } \\
\mathrm{HR}_{\mathrm{Q} 5 \mathrm{vs.Q1}}: 0.55(0.32-0.93) \text { [ER-] } \\
\mathrm{HR}_{\mathrm{Q} 5 \mathrm{vs} 1:} 0.67(0.46-0.98) \text { [PR-] }\end{array}$ & $\begin{array}{l}\text { Country of birth, age at menarche, parity, } \\
\text { duration of lactation, OC, HRT, } \\
\text { menopausal status at baseline, PA, EtOH, } \\
\text { smoking, level of education, energy, BMI }\end{array}$ \\
\hline $\begin{array}{l}\text { Bessaoud et } \\
\text { al. [12] } \\
\text { (France) }\end{array}$ & $\begin{array}{l}\text { Pre and post } \\
\text { Cases: } \\
\mathrm{n}=437 \\
\text { Controls: } \\
\mathrm{n}=922 \\
(25-85 \mathrm{y})\end{array}$ & $\mathrm{CC}$ & $\begin{array}{l}\text { PCA: 1) Western; 2) Meat/ } \\
\text { alcohol; 3) Mediterranean VC: } \\
\text { 1) Western; 2) Raw vegetables } \\
\text { and olive oil; 3) Fish }\end{array}$ & $\begin{array}{l}162 \text {-item } \\
\text { FFQ/BC }\end{array}$ & $\begin{array}{l}\text { PCA: Meat/alcohol pattern: OR: } 1.2 \\
\text { (1.04-1.38) per one } \uparrow \text { S.E VC: Raw } \\
\text { vegetables and olive oil pattern: OR: } \\
1.22(1.06-1.39) \text { per one } \uparrow \text { S.E. }\end{array}$ & $\begin{array}{l}\text { Energy, education, parity, BF age at FFTP, } \\
\text { duration of ovulatory activity, BMI, PA, } \\
\text { first degree of family hx of BC, other } \\
\text { specific patterns (for only VC pattern) }\end{array}$ \\
\hline $\begin{array}{l}\text { Buck et al. } \\
\text { [21] } \\
\text { (Germany) }\end{array}$ & $\begin{array}{l}\text { Post; Cases: } \\
\text { n=3,464; } \\
\text { Controls: } \\
\text { n=6,657; } \\
(50-74 \text { y) }\end{array}$ & $\mathrm{CC}$ & 1) Healthy 2) Unhealthy & $\begin{array}{l}\text { 176-item } \\
\mathrm{FFQ} / \mathrm{BC} \\
\mathrm{BC}\end{array}$ & $\begin{array}{l}\text { Unhealthy Pattern: } \mathrm{OR}_{\mathrm{Q} 2 \mathrm{vs.Q5}}: 1.05 \\
(0.78-1.42) \text { vs. } 0.69(0.49-0.98) \text { for } \\
\mathrm{ER} / \mathrm{PR} \text { - tumors }\end{array}$ & $\begin{array}{l}\text { Birth yr, study ctr, menopausal induction, } \\
\text { BMI, occupation, first degree family BC } \\
\text { hx, benign breast disease hx, \# of preg., } \\
\text { age at menarche, BF hx, total \# of } \\
\text { mammograms, smoking, energy }\end{array}$ \\
\hline $\begin{array}{l}\text { Cade et al. } \\
{[13]} \\
\text { (England) }\end{array}$ & $\begin{array}{l}\text { Pre and post } \\
\mathrm{n}=33,731 \\
(35-69 \mathrm{y})\end{array}$ & PCS & Mediterranean and WHO HDI & $\begin{array}{l}217 \text {-item } \\
\mathrm{FFQ} / \mathrm{BC} \\
\mathrm{BC}\end{array}$ & $\begin{array}{l}\text { Premenopausal women (NS trend): } \\
\text { Maximal adherence to the Med Diet: } \\
\text { HR }=0.65\left(0.42-1.02, \mathrm{p}_{\text {trend }}=0.09\right)\end{array}$ & $\begin{array}{l}\text { Age, energy, menopause, kcal-adj fat, BMI, } \\
\text { PA, OC, HRT, smoking, parity, age at } \\
\text { menarche, EtOH, total days BF, SES, } \\
\text { education }\end{array}$ \\
\hline $\begin{array}{l}\text { Demetriou } \\
\quad[11] \\
\text { (Greece) }\end{array}$ & $\begin{array}{l}\text { Post; Cases: } \\
\text { n=937; } \\
\text { Controls: } \\
\text { n=817 } \\
(40-70 \text { y) }\end{array}$ & $\mathrm{CC}$ & Mediterranean Diet & $\begin{array}{l}\text { 32-item } \\
\text { FFQ/BC }\end{array}$ & $\begin{array}{l}\text { MDS Scores: Null } \\
\frac{\text { PCA: Vegetable, Fish, Fruit, and }}{\text { Legume Pattern OR }} \text { Q4vs.Q1 }_{0}: 0.67 \\
(0.49-92) \text { vs. REF }\end{array}$ & $\begin{array}{l}\text { Age at interview, family hx, age at FFTP, } \\
\text { HRT, } \\
\text { PA, age at menarche, height, BMI \& PCA } \\
\text { derived patterns } 1,2, \& 3 \text { in } \\
\text { postmenopausal women }\end{array}$ \\
\hline \multirow[t]{3}{*}{$\begin{array}{l}\text { Jordan [23] } \\
\text { (Tanzania) }\end{array}$} & \multirow[t]{3}{*}{$\begin{array}{l}\text { Pre and post } \\
\text { Cases: } \\
\mathrm{n}=115 \\
\text { Controls: } \\
\mathrm{n}=230 \\
(26-85 \mathrm{y})\end{array}$} & \multirow[t]{3}{*}{$\mathrm{CC}$} & \multirow[t]{3}{*}{$\begin{array}{l}\text { PCA 1: 1) Diet of the Rich; 2) } \\
\text { Mchicha; 3) Banana; 4) Fatty } \\
\text { PCA 2: 1) Diet of the Rich; 2) } \\
\text { Fruity; 3) Mchicha; 4) Banana; } \\
\text { 5) Starchy; 6) Fatty }\end{array}$} & \multirow[t]{3}{*}{$\begin{array}{l}\text { 65-item } \\
\text { FFQ/BC }\end{array}$} & $\begin{array}{l}\text { PCA 1: } \\
\text { *Banana: OR }_{\mathrm{Q} 4 \mathrm{vQ} \mathrm{l}}: 1.94(1.43-2.63) \\
\text { **Fatty: } \mathrm{OR}_{\mathrm{Q} 4 \mathrm{vs} \mathrm{Q}}: 3.04(1.34-6.91)\end{array}$ & $\begin{array}{l}\text { *Age } \\
\text { **Age, place of living, age at menarche, } \\
\text { menopausal status, Mbege (home-made } \\
\text { beer), beer \& wine }\end{array}$ \\
\hline & & & & & PCA 2: & $\begin{array}{l}* * * \text { Age, place of living, SES, age at } \\
\text { menarche, } \\
\text { age at FTTP, BMI (current \& at age 20), } \\
\text { lifelong lactation }\end{array}$ \\
\hline & & & & & $\begin{array}{l}\text { **Fruity: } \mathrm{OR}_{\mathrm{Q} 4 \mathrm{vs} 1}: 1.61(1.14-2.28) \\
{ }^{* *} \text { Fatty: } \mathrm{OR}_{\mathrm{Q} 4 \mathrm{vs} \mathrm{Q} 1}: 1.42(1.08-1.87)\end{array}$ & $\begin{array}{l}\text {-The Banana Diet was significant after } \\
\text { controlling for other covariates above. }\end{array}$ \\
\hline $\begin{array}{l}\text { Zhang et al. } \\
{[22]} \\
\text { (China) }\end{array}$ & $\begin{array}{l}\text { Pre and post } \\
\text { Cases: } \\
\mathrm{n}=438 \\
\text { Controls: } \\
\mathrm{n}=438 \\
(25-70 \mathrm{y})\end{array}$ & $\mathrm{CC}$ & $\begin{array}{l}\text { 1) Vegetable-fruit-milk-poultry- } \\
\text { fish; 2) Refined grain-meat- } \\
\text { pickle }\end{array}$ & $\begin{array}{l}\text { 81-item } \\
\text { FFQ/BC }\end{array}$ & $\begin{array}{l}\text { Vegetable-fruit-milk-poultry-fish: } \\
\text { OR }_{\mathrm{Q} 4 \mathrm{vs} 4}=0.26(0.17-0.42) \\
\frac{\text { grain-meat-pickle: }}{(1.53-4.34)} \mathrm{OR}_{\mathrm{Q} 4 \mathrm{vsQ} 4}=2.58\end{array}$ & $\begin{array}{l}\text { Age at menarche, live births \& age at first } \\
\text { live birth, months BF, BMI, hx of benign } \\
\text { breast disease, first-degree relative with } \\
\text { BC, PA, passive smoking, energy }\end{array}$ \\
\hline
\end{tabular}

BC, breast cancer; MDS, Mediterranean diet score; PCA, principal component analysis; OR, odds ratio; HR, hazard ratio; OC, oral contraceptives; HRT, hormone replacement therapy; EtOH, alcohol; PA, physical activity; BF, breastfeeding; SES, socioeconomic status; FFTP, first full-term birth; BMI; body mass index; Hx, history; VC, variable clustering; WHO HDI, World Health Organization Healthy Diet Index; FFQ, Food Frequency Questionnaire; SE, standard error; NS, no significance; ER/PR, estrogen receptor/progesterone receptor

identified from the electoral roll. Dietary data were collected within approximately 3 months of diagnosis via a 162 -item validated FFQ that captured diet over the previous year. If diets were deemed to have changed due to cancer diagnosis, only the diet before the change was assessed. The Mediterranean diet pattern derived using the PCA method was not associated with breast cancer risk. However, when the VC method was used, the Mediterranean pattern was split into the "Fish" and "Raw Vegetables and Olive Oil" pattern," which yielded mixed results. The "Fish" pattern tended to be protective (OR 0.93; $95 \%$ CI 0.81-1.07), whereas the "Raw Vegetable and Olive Oil" pattern increased breast cancer risk (OR 1.22; $95 \%$ CI 1.06-1.39). Although the increase in cancer risk with the "Raw Vegetable and Olive Oil" pattern may seem counterintuitive, the authors suggested that this could be due to the large amount of energy from the olive oil negating the beneficial effects of the raw vegetables [12]. This was partially verified when the data were reanalyzed controlling for monounsaturated fatty acids (MUFAs), which led to a nonsignificant inverse association for the "Raw Vegetable and Olive Oil" pattern compared with the previously positive association [12].

Overall, the current state of the literature offers mixed results regarding the Mediterranean dietary pattern and breast cancer risk. It is important to note that none of these studies conducted analyses controlling for or stratifying by the hormone receptor status of the tumor. Previous literature suggests that adherence to the Mediterranean diet can be protective against breast cancer, particularly for estrogen receptor/progesterone receptor (ER/PR) negative tumors 
$[10,17 \cdot]$. Additionally, an earlier study by Trichopoulou et al. $[17 \bullet$ examined the conformity to a traditional Mediterranean diet and breast cancer risk among 14,807 both premenopausal and postmenopausal women in the Greek European Prospective Investigation into Cancer and Nutrition (EPIC) cohort. A total of 240 incident breast cancer cases were ascertained (113 premenopausal and 127 postmenopausal). A significant inverse association between higher adherence to the Mediterranean diet and breast cancer risk was only detected in postmenopausal women (Per 2-point increment, HR 0.78; $95 \%$ CI $0.62-0.98 ; p=0.03)$. It is possible that this particular dietary pattern may only influence breast cancer risk among subgroups of women, such as those who are postmenopausal or have ER/PR-negative tumors.

\section{Healthy/Fruit and Vegetable}

Dietary patterns that are classified as "prudent" or "healthy" are high in fruits and vegetables, vitamins, minerals, healthy fats, and fiber [18••, 19]. Five studies [12, 20-23] used $a$ posteriori methods, and one study [13] used an a priori method (WHO Healthy Diet Index) to identify "healthy" dietary patterns and examine associations with breast cancer risk. Two studies examined the relationship between dietary patterns and breast cancer risk in Chinese [22] and Australian [20] women and observed significant inverse associations between healthy dietary patterns and breast cancer risk. Baglietto and colleagues [20] analyzed data from the Melbourne Collaborative Cohort Study of 20,967 premenopausal and postmenopausal women followed for an average of 14 years. A total of 815 incident cases of adenocarcinoma were identified. Noninvasive in situ breast cancers were not included as cases. Dietary data were collected during a baseline interview with a 121 -item FFQ that was developed for this cohort. This study [20] used factor analysis, an $a$ posteriori method, to derive dietary patterns and found distinct "Vegetable" and "Fruit and Salad" patterns, and other patterns that will be discussed in other sections of this review. A significant inverse association was observed only for the "Fruit and Salad" pattern among ER-negative and PR-negative tumors only $\left(\mathrm{HR}_{\mathrm{Q} 5 \mathrm{vs} . \mathrm{Q} 1} 0.55 ; 95 \%\right.$ CI 0.32 $0.93 ; \mathrm{p}_{\text {trend }}=0.004$; and $\mathrm{HR}_{\mathrm{Q} 5 \mathrm{vs.Q} 1} 0.67 ; 95 \%$ CI 0.46-0.98; $\left.\mathrm{p}_{\text {trend }}=0.01\right)$ for ER-negative and PR-negative status, respectively. The authors indicated that a lack of significant results with the "Vegetable" pattern may potentially be due to vegetable preparation methods. If vegetables are consumed in the cooked versus raw state, loss of nutrients and bioactive components may occur [24]. Zhang et al. [22] performed a hospital-based breast cancer case-control study in Chinese women. Cases $(n=438)$ were eligible for the study if they had an incident confirmed breast cancer diagnosis within 3 months of the interview. Patients with no history of cancer and who were admitted to the same hospital were interviewed for inclusion into the study as ageand residence-matched (rural/urban) controls $(n=438)$. Dietary data were collected with a validated 81 -item FFQ during the initial study interview. This study found that the "Vegetable, Fruit, Milk, Poultry, and Fish" pattern, derived via PCA, was inversely associated with breast cancer $\left(\mathrm{OR}_{\mathrm{Q} 4 \mathrm{vs} 4}=0.26 ; 95 \%\right.$ CI $\left.0.17-0.42 ; \mathrm{p}_{\text {trend }} \leq 0.001\right)$.

Two studies $[13,21]$ found no association and two studies $[12,23]$ found a positive association between healthy dietary patterns and breast cancer risk. Buck and colleagues [21] conducted a large population-based case-control study in postmenopausal German women to examine PCAderived dietary patterns and breast cancer risk. Cases $(\mathrm{n}=$ 2,884 ) were identified through clinics and cancer registries; two controls per case $(n=5,509)$ were chosen at random by using inhabitant registries and matched by age and study center. Diet was assessed via a self-administered, validated 176-item FFQ in all participants reflecting diet over the previous year. All dietary data on cases were collected within a year of diagnosis. A "Healthy" dietary pattern was identified that was high in fruits and vegetables, but also in oil and vinegar dressing and mayonnaise. No association was observed with the "healthy" pattern and breast cancer risk. The authors propose that the lack of association may be attributed to the initiation of a healthy diet later in life when the impact on cancer risk may not be as strong. Finally, "Healthy/Prudent" patterns often are not characterized by high amounts of fats, which may have negated some potential associations. Cade and colleagues [13] examined the World Health Organization's Healthy Eating Index (WHO-HDI) and breast cancer risk in a cohort of premenopausal and postmenopausal women from the UK Women's Cohort Study and observed no association with breast cancer risk.

A French population-based case-control study used variable VC and PCA to identify dietary patterns and examine their associations with breast cancer risk [12]. Only the VC method identified a "Raw Vegetable and Olive Oil" pattern. The investigators concluded that this pattern was significantly associated with a $22 \%$ increase in odds of developing breast cancer per increase in standard error (OR 1.22; $95 \%$ CI 1.06-1.39, per one standard error) [12]. Jordan and colleagues [23] conducted a hospital-based case-control study in Tanzania that examined the effect of dietary patterns on breast cancer risk in both premenopausal and postmenopausal women. Compared with other populations in this review, this group generally has a lower socioeconomic status and cancer prevention information is less accessible. Cases were identified by a primary breast cancer diagnosis and controls were matched by age and district of residency. A total of 115 cases and 230 controls were recruited which included both premenopausal and postmenopausal women 
aged $26-85$ years. An interviewer collected all dietary data with a 65 -item validated questionnaire for the population. The diet in the region is very homogeneous; hence, the limited number of foods included. Much like the French study, a similar effect of the "Fruity Diet" was observed with adherence to this dietary pattern associated with a $61 \%$ higher odds of developing breast cancer (OR 1.61; $95 \%$ CI 1.14-2.28; $p=0.01$ ) [23]. Although the "Fruity Diet" was comprised of several chemoprotective dietary components, such as antioxidants and healthy fats in fish, avocados, and mangos, it also was associated with a reduced intake of polyunsaturated fats (PUFAS). In this study, the PUFA: SFA ratio was inversely associated with breast cancer risk; therefore, the "Fruity Diet" pattern also was characterized by an unfavorable fatty acid ratio [23]. The authors noted that the study was moderately powered, the results should be interpreted with caution, and that larger studies are needed to confirm these findings.

The WCRF/AICR [1] has recently reviewed the evidence on fruits and vegetables and have not found conclusive evidence to support a protective relationship with breast cancer. This may be due in part to analyses in many studies that only examined single foods, which may not account for the synergistic effects of nutrients when foods are consumed together. As mentioned previously, raw fruits and vegetables may be more beneficial due to reduced nutrient loss in the cooking process [24]. Both studies that observed an inverse association with the "healthier" pattern $[20,22]$ had higher factor loadings (which indicates a higher consumption) of fruits, which often are consumed raw compared with vegetables [25, 26]. Buck and colleagues [21] evaluated dietary patterns and breast cancer risk in postmenopausal German women described earlier. No association was observed with the "healthy" pattern characterized by higher factor loadings of vegetables compared to fruits.

\section{Western/Unhealthy/Meat}

Five studies derived dietary patterns that were high in refined grains, meat, alcohol, fat, and other "unhealthy" dietary components [12, 20-23]. Three studies [12, 22, 23] found significant positive associations, whereas one [21] found an inverse association, and one [20] found no association for an "unhealthy" pattern with breast cancer risk. Jordan and colleagues [23] examined dietary patterns in a previously described Tanzanian population two separate ways: one PCA included alcohol, whereas the other did not. Research on alcohol intake and breast cancer risk has shown a consistent and strong positive association [1]. Although alcohol consumption was considered to be low in this population $(<1 \mathrm{drink} /$ day $)$, the authors chose to evaluate the patterns with and without alcohol to determine if alcohol was driving the effects of the patterns. Whereas slight discrepancies in patterns were observed between the two analyses, the "Fatty diet" was clearly characterized by high amounts of milk, butter and lard, vegetable oils, and other fats using both methods and was significantly positively associated with higher breast cancer risk $\left(\mathrm{OR}_{\mathrm{Q} 4 \mathrm{vs} Q 1} 3.04\right.$; $95 \%$ CI 1.34-6.91; $p=0.01$ [PCA1]; and $\mathrm{OR}_{\mathrm{Q} 4 \mathrm{vsQ} 1} 1.43$; $95 \%$ CI 1.08-1.9; $p=0.01$ [PCA $2-$ no alcohol]). Zhang and colleagues [22] derived dietary patterns via PCA in a previously described Chinese hospital-based, case-control study including 438 premenopausal and postmenopausal cases and 438 matched controls. This study found that those who had the highest adherence to the "refined grain-meatpickle" dietary pattern had 2.58 times the odds of developing breast cancer compared with the lowest quartile $\left(\mathrm{OR}_{\mathrm{Q} 4 \mathrm{vs} 1} 2.58 ; 95 \% \mathrm{CI} 1.53-4.34 ; \mathrm{p}_{\text {trend }}<0.001\right)$. A case-control study by Bessaoud and colleagues [12] observed a $20 \%$ higher odds of developing breast cancer per one-increment increase in standard error of the "Meat-eaters and Drinkers" pattern (OR 1.2; 95 \% CI 1.04-1.39).

In contrast, a German study by Buck and colleagues [21] found an inverse association with the "Unhealthy" pattern and ER/PR-negative tumors $\left(\mathrm{OR}_{\mathrm{Q} 2 \text { vs.Q5 }} 1.05 ; 95 \% \mathrm{CI} 0.78\right.$ 1.42 vs. $0.69 ; 95 \%$ CI $0.49-0.98 ; p_{\text {trend }}=0.02$ ). This pattern was more suggestive of a traditional German diet that was low in sweets and desserts and high in potatoes, onions, garlic, and grains, which may not be consistent with the "Unhealthy" patterns described in other research [21]. Finally, Baglietto et al. [20] found no association with an $a$ posteriori "Meat" pattern in a cohort of premenopausal and postmenopausal Australian women.

\section{Traditional to Country}

Two studies found patterns that were very specific to the culture of the country. In the previously described prospective cohort study conducted by Baglietto et al. [20], the investigators identified a "Traditional Australian" pattern characterized by high intakes of dairy products and margarine; however, no association with breast cancer risk was observed. Jordan et al. [23] found several patterns using two different principal component analyses, including "Mchicha," "Banana," "Starchy," and "Diet of the Rich" patterns in a Tanzanian population. Other patterns were observed, which were discussed previously. The "Mchicha diet" was characterized by amaranth leaves, onions, and tomatoes, traditional to Tanzania, and was initially found to be significantly positively associated with breast cancer $\left(\mathrm{OR}_{\mathrm{Q} 4 \mathrm{vs} 1}\right.$ 1.47; $95 \%$ CI 1.14-1.88, $p=0$ ). However, after controlling for socioeconomic and reproductive factors, this relationship was attenuated and no longer significant. The "Banana diet"- distinguished by high intakes of ripe and green 
bananas, sugar, and Mbege, a homemade beer from bananas and millet-was significantly associated with higher odds of elevated breast cancer risk $\left(\mathrm{OR}_{\mathrm{Q} 4 \mathrm{vs} 1}\right.$ 1.94; $95 \%$ CI 1.46-2.63, $p=0)$. When alcohol was removed from this pattern and analyzed separately, the pattern results were no longer significant. Although this suggests that alcohol was driving the detrimental effects of this particular pattern, when alcohol was analyzed apart from the dietary patterns, no independent effect was observed. The authors suggest that this was due to low alcohol consumption in this population $(8.2 \mathrm{~g} /$ day $)$ which did not allow for differences to be observed [23].

\section{Discussion}

This review included seven studies conducted across a variety of countries and cultures. Overall, dietary patterns that were associated with a decrease in breast cancer risk often were composed of similar components, including higher intakes of fresh fruits, vegetables, and lean protein and lower intakes of fat, meat, and alcohol. Several factors may have contributed to variability across study results, including differences in food production, preparation, processing, and storage methods that could alter the true effects of foods, food groups, and dietary patterns on cancer risk.

Dietary patterns may influence different aspects of the development of breast cancer. For example, alcohol has been shown to consistently increase breast cancer risk [1] through many proposed mechanisms, including the alteration of estrogen metabolism and receptor status and increased exposure to harmful metabolites that damage DNA [27•]. Other components of the diet, such as vitamin $\mathrm{D}$ and calcium, may influence breast density, which is a strong risk factor for breast cancer [28-30]. Also, certain nutrients may be more influential on breast cancer risk only after reaching a threshold that promotes tumor development; thus, the baseline rate of consumption in a population may dictate when associations are observed [31]. The influence of particular dietary patterns also may be stronger across different stages of the lifespan. The majority of breast development occurs during puberty. Exposure to unfavorable dietary patterns during childhood and adolescence may influence longterm breast development through promoting early menarche and tallness [1]. None of the studies examined by this review attempted to assess relationships among both current and youth diet with breast cancer risk.

The majority of studies included in this review used either PCA or FA to derive dietary patterns. Although these methods differ slightly, they share qualities that allow for comparison of results across studies. However, a posteriori approaches require several subjective decisions for the classification of foods into larger food groups and the number of patterns to keep, which may limit their reproducibility, even when using the same data [32]. One study used both VC and PCA to obtain dietary patterns in the same dataset and found that the different methods produced slightly different patterns [12]. While a particular method of analysis has not been deemed superior, it is important to recognize these differences when comparing studies.

All but two studies were case-control in design, which increases the possibility of recall bias of food intake. All studies used food frequency questionnaires (FFQs) that commonly assessed diet over the previous year; however, this may have not captured during the time periods that are influential for breast cancer risk. The onset of "unhealthy" dietary patterns tends to occur in childhood, which may lead to weight gain, an earlier age at menarche, and an increase in height, all of which have been associated with increased breast cancer risk $[13,33]$. Diet quality may improve over time, which would not be captured by an FFQ designed to capture dietary intake over the previous year [21].

\section{Conclusions}

The current literature evaluating the relationship between dietary patterns and breast cancer risk remains somewhat mixed. The newest contributions to the literature over the past year provide insight into several cultural dietary patterns and suggest that the "Western/Unhealthy" dietary pattern may, in fact, have an adverse effect on breast cancer risk. They also address several shortcomings of the research and suggest potential future directions. Capturing diet during critical periods of breast development and developing and validating consistent dietary pattern methodologies are important steps that may move the field forward. In addition, evaluating the influence of dietary patterns on breast cancer risk with consideration of tumor characteristics (e.g., hormone receptor status) may provide additional insights. Previous research has reported differences in the association between diet and cancer across breast tumor subtypes [20,21], which suggests that this may be an important factor to examine in future studies.

Disclosures Jessica A. Lindgren and Jennifer Savage-Williams declare that they have no conflict of interest. Jacqueline A. Vernarelli is supported by a grant from the American Institute for Cancer Research. Terryl J. Hartman is supported by grants from the American Institute for Cancer Research, the National Institutes of Health, and the Komen 
Foundation, and she has received compensation from the International Life Sciences Institute for the preparation of a manuscript.

\section{References}

Papers of particular interest, published recently, have been highlighted as:

- Of importance

-• Of major importance

1. WCRF/AICR: Food, Nutrition, Physical Activity, and the Prevention of Cancer: A Global Perspective. In: Edited by Research WCRFAIfC. Washington, D.C.; 2007.

2. Colditz GA, Frazier AL. Models of breast cancer show that risk is set by events of early life: prevention efforts must shift focus. Cancer Epidemiol Biomarkers Prev. 1995;4(5):567-71.

3. American Cancer Society. Available at www.cancer.org. Accessed November 2012.

4. Edefonti V, Randi G, La Vecchia C, et al. Dietary patterns and breast cancer: a review with focus on methodological issues. Nutr Rev. 2009;67(6):297-314.

5. Guenther PM, Reedy J, Krebs-Smith SM. Development of the healthy eating index-2005. J Am Diet Assoc. 2008;108(11):1896-901.

$6 . \bullet$ Brennan SF, Cantwell MM, Cardwell CR, et al. Dietary patterns and breast cancer risk: a systematic review and meta-analysis. Am J Clin Nutr. 2010;91(5):1294-302. Brennan and colleagues conducted a systematic review and meta-analysis on studies that examined dietary patterns and breast cancer risk up to November 2009. This study observed an inverse association with "prudent/ healthy" patterns, a positive association with "drinker" patterns, and no associations with "Western/unhealthy" patterns.

7. •- Sofi F, Abbate R, Gensini GF, et al. Accruing evidence on benefits of adherence to the Mediterranean diet on health: an updated systematic review and meta-analysis. Am J Clin Nutr. 2010;92(5):1189-96. Sofi and colleagues updated a former metaanalysis with recent literature on the Mediterranean diet and its protective properties of chronic disease. This paper confirmed that higher conformity to the Mediterranean diet caused significant decreases in overall mortality as well as cardiovascular, neoplastic, and neurodegenerative diseases.

8. Martinez-Gonzalez MA, Fernandez-Jarne E, Serrano-Martinez M, et al. Mediterranean diet and reduction in the risk of a first acute myocardial infarction: an operational healthy dietary score. Eur J Nutr. 2002;41(4):153-60.

9. Fung T, Hu FB, Fuchs C, et al. Major dietary patterns and the risk of colorectal cancer in women. Arch Intern Med. 2003;163(3):309-14.

10. Cottet V, Touvier M, Fournier A, et al. Postmenopausal breast cancer risk and dietary patterns in the E3N-EPIC prospective cohort study. Am J Epidemiol. 2009;170(10):1257-67.

11. Demetriou CA, Hadjisavvas A, Loizidou MA, et al. The mediterranean dietary pattern and breast cancer risk in Greek-Cypriot women: a case-control study. BMC Cancer. 2012;12:113.

12. Bessaoud F, Tretarre B, Daures JP, et al. Identification of dietary patterns using two statistical approaches and their association with breast cancer risk: a case-control study in Southern France. Ann Epidemiol. 2012;22(7):499-510.

13. Cade JE, Taylor EF, Burley VJ, et al. Does the Mediterranean dietary pattern or the Healthy Diet Index influence the risk of breast cancer in a large British cohort of women? Eur J Clin Nutr. 2011;65(8):920-8.

14. Panagiotakos DB, Pitsavos C, Arvaniti F, et al. Adherence to the Mediterranean food pattern predicts the prevalence of hypertension, hypercholesterolemia, diabetes and obesity, among healthy adults; the accuracy of the MedDietScore. Prev Med. 2007;44(4):335-40.
15. Trichopoulou A, Costacou T, Bamia C, et al. Adherence to a Mediterranean diet and survival in a Greek population. $\mathrm{N}$ Engl $\mathrm{J}$ Med. 2003;348(26):2599-608.

16. WHO Technical Report Series. In: Diet, Nutrition, and the Prevention of Chronic Diseases Report of a Joint WHO/FAO Expert Consultation 2003. Geneva: World Health Organization; 2003.

17. - Trichopoulou A, Bamia C, Lagiou P, et al. Conformity to traditional Mediterranean diet and breast cancer risk in the Greek EPIC (European Prospective Investigation into Cancer and Nutrition) cohort. Am J Clin Nutr. 2010;92(3):620-5. This study examines the Mediterranean diet among both pre- and postmenopausal women as well as by tumor type and finds differences between both menopausal status and tumor status. Much like Cottet and colleagues (2009), Trichopoulou et al. emphasizes the importance of taking these characteristics into consideration when examining the Mediterranean diet.

18. Kant AK. Dietary patterns: biomarkers and chronic disease risk. Appl Physiol Nutr Metab. 2010;35(2):199-206. Kant and colleagues reviewed prospective cohort studies and randomized, controlled trials and summarized information on dietary patterns and disease risk. This study provides additional background information on the association between diseases and mortality and their relationships with different dietary patterns.

19. Millen BE, Quatromoni PA, Pencina M, et al. Unique dietary patterns and chronic disease risk profiles of adult men: the Framingham nutrition studies. J Am Diet Assoc. 2005;105(11):1723-34.

20. Baglietto L, Krishnan K, Severi G, et al. Dietary patterns and risk of breast cancer. Br J Cancer. 2011;104(3):524-31.

21. Buck K, Vrieling A, Flesch-Janys D, et al. Dietary patterns and the risk of postmenopausal breast cancer in a German case-control study. Cancer Causes Control. 2011;22(2):273-82.

22. Zhang CX, Ho SC, Fu JH, et al. Dietary patterns and breast cancer risk among Chinese women. Cancer Causes Control. 2011;22(1):115-24.

23. Jordan I, Hebestreit A, Swai B et al.: Dietary patterns and breast cancer risk among women in northern Tanzania: a case-control study. Eur J Nutr .2012.

24. Link LB, Potter JD. Raw versus cooked vegetables and cancer risk. Cancer Epidemiol Biomarkers Prev. 2004;13(9):1422-35.

25. Newby PK, Tucker KL. Empirically derived eating patterns using factor or cluster analysis: a review. Nutr Rev. 2004;62(5):177-203.

26. Brantsaeter AL, Haugen M, Samuelsen SO, et al. A dietary pattern characterized by high intake of vegetables, fruits, and vegetable oils is associated with reduced risk of preeclampsia in nulliparous pregnant Norwegian women. J Nutr. 2009;139(6):1162-8.

27. - Coronado GD, Beasley J, Livaudais J. Alcohol consumption and the risk of breast cancer. Salud Publica Mex. 2011;53(5):440-7. Coronado and colleagues examined the well-studied association between alcohol and breast cancer and further explained potential mechanisms through which alcohol can be contributing to tumor formation.

28. Berube S, Diorio C, Verhoek-Oftedahl W, et al. Vitamin D, calcium, and mammographic breast densities. Cancer Epidemiol Biomarkers Prev. 2004;13(9):1466-72.

29. Berube S, Diorio C, Masse B, et al. Vitamin D and calcium intakes from food or supplements and mammographic breast density. Cancer Epidemiol Biomarkers Prev. 2005;14(7):1653-9.

30. Diorio C, Berube $\mathrm{S}$, Byrne $\mathrm{C}$, et al. Influence of insulin-like growth factors on the strength of the relation of vitamin $\mathrm{D}$ and calcium intakes to mammographic breast density. Cancer Res. 2006;66 (1):588-97.

31. Wynder EL, Cohen LA, Muscat JE, et al. Breast cancer: weighing the evidence for a promoting role of dietary fat. J Natl Cancer Inst. 1997;89(11):766-75.

32. Martinez ME, Marshall JR, Sechrest L. Invited commentary: factor analysis and the search for objectivity. Am J Epidemiol. 1998;148(1):17-9.

33. Key TJ, Verkasalo PK, Banks E. Epidemiology of breast cancer. Lancet Oncol. 2001;2(3):133-40. 